\title{
Functional analysis of a lung cancer risk haplotype in the ILIB gene regulatory region
}

\author{
Nina E Landvik, Kent Hart, Aage Haugen and Shanbeh Zienolddiny

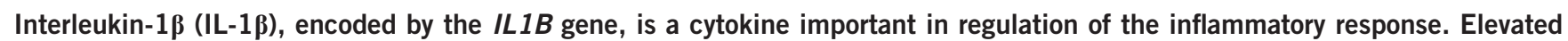 \\ levels of $I L 1 B$ expression have been associated with risk of gastric and lung cancer. We previously reported that a certain \\ haplotype containing four single-nucleotide polymorphisms (SNPs) ( $-3893 \mathrm{G},-1464 \mathrm{G},-511 \mathrm{C}$ and $-31 \mathrm{~T}$; GGCT) in the \\ $I L 1 B$ gene regulatory region was associated with lung cancer risk and increased expression of the IL1B gene in the lung. In the \\ present study, we have cloned the two haplotypes that were either protective (ACTC) or increasing lung cancer risk (GGCT) in a \\ luciferase reporter vector system. We also cloned the IL1B -3893 and -1464 SNPs that were found to be associated with \\ risk of lung cancer. The haplotype associated with lung cancer risk showed higher transcriptional activity in the human lung \\ epithelial A549 cell line in vitro. We also found that the IL1B -1464 C allele increased transcriptional activity compared with \\ the $-1464 \mathrm{G}$ allele in the tumor necrosis factor $\alpha$-stimulated cells, as well as specific transcription factor binding patterns to \\ the IL1B $-1464 C$ allele. Interestingly, in vitro results showed a similar expression pattern as observed in the normal lung \\ tissues of lung cancer patients reported earlier.
}

Journal of Human Genetics (2012) 57, 747-752; doi:10.1038/jhg.2012.106; published online 6 September 2012

Keywords: carcinogenesis; haplotype; IL1B; inflammation; lung cancer; SNP

\section{INTRODUCTION}

Interleukin-1 $\beta$ (IL-1 $\beta$ ) is a highly inflammatory cytokine, which expression is upregulated in different cancer types such as breast, colon, melanomas and lung cancer. ${ }^{1,2}$ The regulatory region of the $I L 1 B$ gene extends over $3 \mathrm{~kb}$ from the transcription start site, ${ }^{3}$ an area containing several single-nucleotide polymorphisms (SNPs). IL1B gene expression may be modified by genetic polymorphisms in the gene. ${ }^{4,5}$ We have previously studied SNPs in the ILIB gene regulatory region in a Norwegian lung cancer case control study. ${ }^{5}$ We found higher frequency of a haplotype containing four SNPs (G-3893A, G-1464C, C-511T and T-31C), where -3893G, -1464G, -511C and $-31 \mathrm{~T}$ were associated with lung cancer risk and higher expression of the $I L 1 B$ gene in normal lung tissue from lung cancer patients. ${ }^{5} \mathrm{~A}$ few prior studies have investigated the $-1464,-511$ and -31 SNPs either as a haplotype or single SNPs, ${ }^{5-13}$ but little is known about the IL1B -3893 SNP. Epidemiological studies show risk association with the $I L 1 B-511 \mathrm{SNP},{ }^{7,13}$ but functional studies show little biological evidence for this polymorphism, and therefore IL1B - 1464 and -31 SNPs have received more attention. ${ }^{6,7,9,10}$ Unique transcription factor binding patterns have been observed for both IL1B - 1464 and $-31.6,7,9,10$ Our group recently identified the transcription factor Yin Yang 1 (YY1) as part of the transcription factor complex that bound specifically to the $I L 1 B-31 \mathrm{C}$ allele, and that YY1 binding to the IL1B promoter also altered the expression of the $I L 1 B$ gene. ${ }^{14}$ As these four
SNPs are tightly linked in the Norwegian lung cancer cases, we attempted to evaluate the effect of the haplotypes, as well as the effect of single SNPs, on transcriptional activity of the $I L 1 B$ gene promoter. To do this, we constructed luciferase reporter vectors containing the protective ACTC and the risk GGCT haplotypes. We also constructed vectors surrounding the IL1B G-3893A and G-1464C SNPs and analyzed transcriptional activities in the human lung epithelial cell line A549. Furthermore, we analyzed, by using electrophoretic mobility shift assay (EMSA) and supershift assay, specific transcription factor binding patterns surrounding the -1464 and -3893 SNPs. We found unique transcription factor binding patterns around the $-1464 \mathrm{C}$ allele, and found that the $-1464 \mathrm{C}$-allele that was considered as the non-risk allele resulted in increased transcriptional activity; however, the combined effect of the lung cancer risk haplotype $(-3893 \mathrm{G},-1464 \mathrm{G},-511 \mathrm{C}$ and $-31 \mathrm{~T})$ had higher transcriptional activity compared with the haplotype that showed protective effects. These data support the notion that a haplotype in the $I L 1 B$ gene regulatory region is associated with increased expression of $I L 1 B$ and increased lung cancer risk.

\section{MATERIALS AND METHODS}

Construction of IL1B haplotype

A sequence of $1011 \mathrm{bp}$ containing the most frequent IL1B haplotypes associated with lung cancer risk were cloned into the pGL3-basic reporter 
vector (Promega, Madison, WI, USA) upstream of the firefly luciferase coding region. The cloning was performed by Genscript USA Inc. (Piscataway, NJ, USA). After cloning the orientation and integrity of the sequence were verified by sequencing, the sequences varied only in the SNP positions. The reporter vector inserts were designed as follows: 200 bp surrounding the IL1B G-3893A (rs12621220) SNP, 200 bp surrounding the IL1B G-1464C (rs1143623) SNP and $599 \mathrm{bp}$ from transcription start site containing the IL1B C-511T (rs16944) and IL1B T-31C (rs1143627) SNPs. The sequences are corresponding to positions $-3798 /-3998,-1372 /-1572$ and $-1 /-600$ in the IL1B regulatory region. Exact sequences can be viewed in Supplementary Table 1. The insert sequences were added recognition sites for restriction enzymes MluI and BglII, respectively. Plasmids were amplified and purified by the use of Endofree Plasmid Maxi Kit (Qiagen, Hilden, Germany), concentrations were accurately determined by PicoGreen assay (Molecular Probes, Eugene, OR, USA).

\section{Construction of IL1B -1464 and -3893 vectors}

pGL3-basic reporter vectors (Promega) does not contain any known promoter or enhancer sequences and were used to construct IL1B -1464 and -3893 vectors. DNA from individuals homozygote for $-1464 \mathrm{G} / \mathrm{G}$ or $\mathrm{C} / \mathrm{C}$ were amplified by the use of PCR using the primers forward $5^{\prime}$-ACGCGTTCTGC AGGACCAGACACCA- $3^{\prime}$ and reverse $5^{\prime}$-AGATCTGAGTTGAAACCTTGCTCC

Table 1 Sequences of probes used in EMSA and supershift experiments

\begin{tabular}{|c|c|}
\hline SNP & Sequence, $X=$ biotin labeling \\
\hline IL1B $-1464 G$ & 5'-XCTCACTCCCTTGGATAATGCAGAGCGAGCA-3' \\
\hline IL1B -1464G complementary & 5'-TGCTCGCTCTGCATTTATCCAAGGGAGTGAG-3' \\
\hline IL1B $-1464 C$ & 5'-ХCTCACTCCСTTGCATAÄTGCAGAGCGAGCA-3' \\
\hline IL1B $-1464 C \mathrm{c}$ & 5'-TGCTCGCTCTGCATTATGCAAGGGAGTGAG-3' \\
\hline IL1B $-3893 G$ & 5'-XATGGATCCAAAGGAAGGGACAAGGTCTTATT-3' \\
\hline IL1B -3893G complementary & 5'-AATAAGACCTTGTCCTTCCTTTGGATCCAT-3' \\
\hline IL1B $-3893 A$ & 5-XATGGATCCAAAGGĀAAGACAAGGTCTTATT-3' \\
\hline IL1B -3893A complementary & 5'-AATAAGACCTTGTCTTTTCCTTTGGATCCAT-3' \\
\hline
\end{tabular}

Abbreviation: EMSA, electrophoretic mobility shift assay.
TCC-3' and HOT FIREPol DNA Polymerase (Solis BioDyne, Tartu, Estonia). The 471-bp sequence, corresponding to position $-1289 /-1760$ in the IL1B regulatory region, was cloned into the reporter vector. $I L 1 B-3893$ vectors were constructed in a similar manner and DNA from individuals homozygote for $-3893 \mathrm{G} / \mathrm{G}$ or $\mathrm{A} / \mathrm{A}$ were amplified by PCR using the primers forward $5^{\prime}-A C G$ CGTTGGCACTTAGTAGGTGCTCAA- $3^{\prime}$ and reverse $5^{\prime}$-AGATCTCGAGCTAT GTAGTCTCCAATGG-3'. The 456-bp sequence corresponds to position $-3819 /-4275$ in the IL1B regulatory region. The forward and reverse primers contained recognition sites for restriction enzymes MluI and BglII, respectively. After cloning the integrity and orientation of the insert were verified by sequencing (ABI-lab, Oslo, Norway). Plasmids were amplified and purified by the use of Endofree Plasmid Maxi Kit (Qiagen, Hilden, Germany); concentrations were accurately determined by PicoGreen assay (Molecular Probes).

\section{Cell culture}

A549 was purchased from the European Collection of Cell Culture (Salisbury, UK) and maintained in DMEM F12 medium (supplemented with 10\% heatinactivated FBS, $100 \mathrm{~nm}$ hydrocortisone, $5 \mu \mathrm{g} \mathrm{ml}^{-1}$ insulin, $5 \mu \mathrm{g} \mathrm{ml}^{-1}$ transferrin, $5 \mathrm{ng} \mathrm{ml}^{-1}$ sodium selenite, $15 \mathrm{~mm}$ HEPES, $2 \mathrm{~mm}$ L-glutamin, $100 \mathrm{U} \mathrm{ml}^{-1}$ penicillin and $100 \mu \mathrm{g} \mathrm{ml}^{-1}$ streptomycin). The cells were kept at $37^{\circ} \mathrm{C}$ in $5 \%$ $\mathrm{CO}_{2}$. Different numbers of cells were seeded in dishes or plates 1 day before exposure at a density of $3.5 \times 10^{4} \mathrm{cells} \mathrm{cm}^{-2}$. During all treatments, cells in logarithmic growth were used. Cells were exposed to various concentrations of tumor necrosis factor alpha (TNF $\left.\alpha ; \mathrm{ng} \mathrm{ml}^{-1}\right)$ during $1 \mathrm{~h}$.

\section{Transient transfection and luciferase measurement}

A549 cells were transfected using the lipofectamine-LTX and Plus Reagent (Invitrogen, Carlsbad, CA, USA) according to the supplied protocol. One microgram of constructed reporter vector or control reporter vector were cotransfected with $100 \mathrm{ng}$ of pRL-TK vector (Promega) in DMEM:F12 without antibiotics. The pRL-TK contains a Renilla luciferase gene downstream of the herpes simplex virus thymidine kinase promoter and served as an internal control for transfection efficiency. After $24 \mathrm{~h}$ transfection, the transfection medium was discarded and the cells were either exposed to $15 \mathrm{ng} \mathrm{ml}^{-1} \mathrm{TNF} \alpha$ (Sigma, St Louis, MO, USA) or vehicle in medium for $1 \mathrm{~h}$ and then lysed using Passive Lysis Buffer (Promega). Luciferase activity was measured in the cell lysates using the Dual Luciferase assay (Promega), allowing both firefly and

a

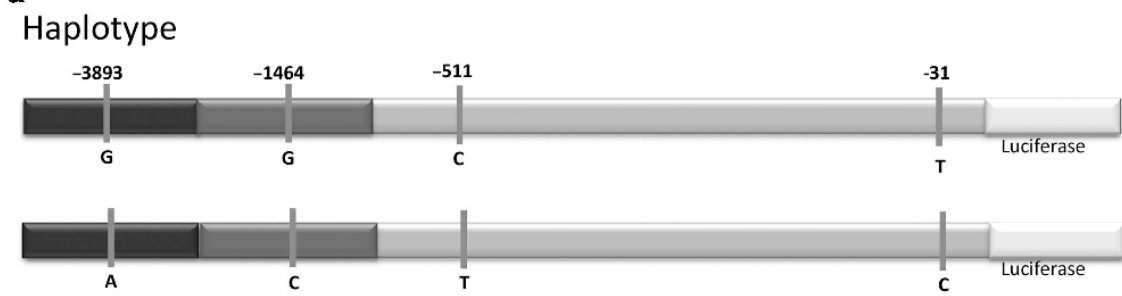

b

IL1B -3893
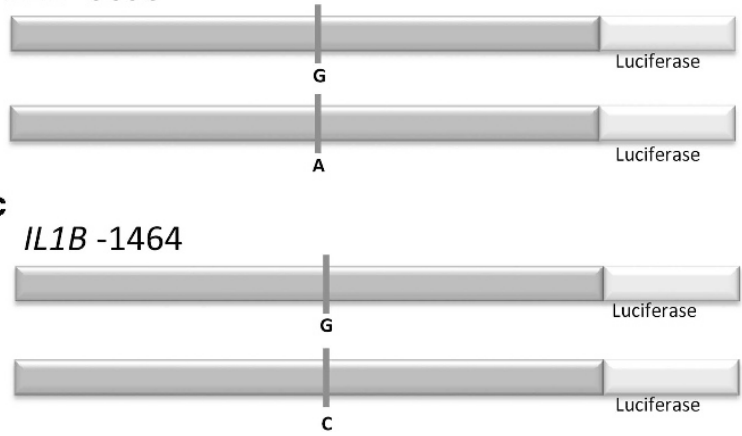

Figure 1 Luciferase promoter vector constructs. Scheme of the luciferase promoter vector constructs for the vectors studied, ILIB GGCT and ACTC haplotype vectors (a), IL1B G-3893A vectors (b) and IL1B G-1464C vectors (c). 
Renilla luciferase to be measured from the same sample in a Modulus microplate reader (Turner Biosystems, Sunnivale, CA, USA). Promoter activity was measured as the ratio between firefly and Renilla luciferase and normalized to the control vector ratio. At least three experiments were performed, each consisting of two independent transfections with each construct.

\section{Preparation of nuclear extracts}

Nuclear proteins were extracted from A549 cells using the method previously described. ${ }^{10}$ Briefly, $4 \times 10^{7}$ cells were seeded and exposed the next day with or without $15 \mathrm{ng} \mathrm{ml}^{-1} \mathrm{TNF} \alpha$ for $1 \mathrm{~h}$ before the cells were collected by scraping, washed in PBS and collected by centrifugation. Cells were then resuspended in a hypotonic buffer (10 mM Hepes-KOH, pH 7.9; $1.5 \mathrm{~mm} \mathrm{MgCl}_{2} ; 10 \mathrm{~mm} \mathrm{KCl}$; $0.5 \mathrm{~mm}$ DTT) and allowed to swell on ice for $10 \mathrm{~min}$. Following centrifugation, cells were homogenized and lysed in the hypotonic buffer containing $0.05 \%$ NP-40 using a dounce homogenizer (pestle B). Nuclei were collected by centrifugation, resuspended in a hypertonic buffer $(40 \mathrm{~mm}$ Hepes- $\mathrm{KOH}, \mathrm{pH}$ 7.9; $0.4 \mathrm{M} \mathrm{KCl} ; 10 \%$ glycerol; $1 \mathrm{~mm}$ DTT) and lysed by the addition of $\mathrm{NaCl}$ to a final concentration of $300 \mathrm{~mm}$. Lysates were cleared by centrifugation at 25000 r.p.m. for $30 \mathrm{~min}$, snap frozen in liquid nitrogen and stored at $-70{ }^{\circ} \mathrm{C}$. Protein concentration was determined using the BCA protein assay kit (Pierce Biotechnology Inc., Rockford, IL, USA).

\section{Electrophoretic mobility shift assay}

Sequences for synthetically manufactured biotin labeled or unlabeled DNAoligos were purchased (DNA Technology, Aarhus, Denmark). The 30-bp sequences surrounding the IL1B -3893 and -1464 SNPs used in the EMSA experiments can be viewed in Table 1. Equimolar amounts of each strand were combined in annealing buffer $(10 \mathrm{~mm}$ Tris, $1 \mathrm{~mm}$ EDTA and $50 \mathrm{~mm} \mathrm{NaCl})$ and denatured in a water bath for $5 \mathrm{~min}$. The mixture was then allowed to cool slowly in the water bath to form double stranded probes for use in binding reactions. EMSA assays were performed by using the LightShift chemiluminescent EMSA kit (Thermo Fisher Scientific, Rockford, IL, USA). Binding reactions contained $20 \mathrm{fmol}$ biotin labeled double stranded probe, 7-8 $\mu \mathrm{g}$ nuclear extract and $1.0 \mu \mathrm{g}$ poly $(\mathrm{dI}-\mathrm{dC})$ in a total volume of $20 \mu \mathrm{l}$ binding buffer (10 mм Tris, $50 \mathrm{~mm} \mathrm{KCl,} 3 \mathrm{~mm} \mathrm{MgCl}_{2}, 0.1 \mathrm{~mm}$ EDTA and $1.0 \mathrm{~mm}$ DTT). Complexes were allowed to form for $20 \mathrm{~min}$ at room temperature before separation on a $5 \%$ native polyacrylamide gel. Probes were then blotted onto a positively charged nylon membrane (Millipore, Billerica, MA, USA) and visualized according to the LightShift protocol. For competition experiments, 200 -fold molar excess of unlabeled probe was added before the addition of labeled probe. Supershift reaction was performed by the addition of $2.0 \mu \mathrm{g}$ TranzCruz antibody raised against CCAAT/enhancer-binding protein beta $(\mathrm{CEBP} / \beta)$ according to the supplier's protocol (Santa Cruz Biotechnology Inc., Santa Cruz, CA, USA).

\section{a}
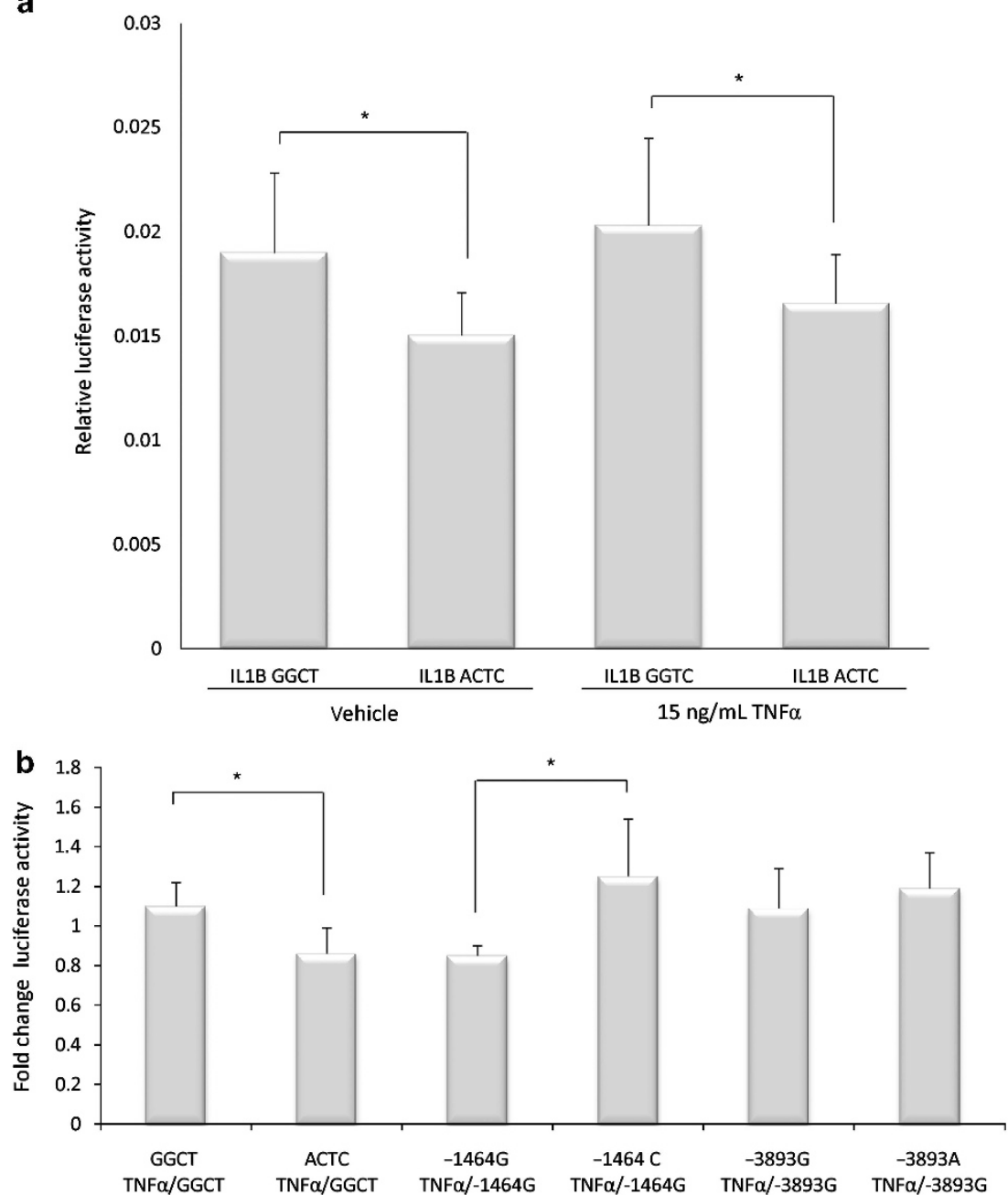

Figure 2 Luciferase promoter vector activity. (a) Relative luciferase activity for the haplotype vectors exposed (right panel) or not (left panel) to $15 \mathrm{ng} \mathrm{ml}^{-1}$ TNF $\alpha$ for $1 \mathrm{~h}$. (b) Fold change in luciferase activity for haplotype, -1464 and -3893 vectors exposed to $15 \mathrm{ngml}^{-1} \mathrm{TNF}_{\alpha}$. The data were normalized to wild type unexposed vector. The data are mean \pm s.e. for seven independent experiments. Asterisk denotes significant difference $(P<0.05)$. 
Statistical analysis

All data are quoted as mean \pm standard error, the number of observations, $n$, corresponding to separate cultures was always more than three. ANOVA followed by a Student-Newman-Keuls post-test was used to compare means. $P<0.05$ was chosen for cutoff levels of statistical significance. All statistical analyzes were performed using the PASW statistics 18 statistical package (SPSS, Inc, Chicago, IL, USA).

\section{RESULTS}

Increased transcriptional activity for the IL1B GGCT haplotype The lung epithelial cell line A549 was transfected with each of the constructed vectors containing the haplotypes, the IL1B -3893 SNP, the $I L 1 B-1464$ SNP or a control vector as described in Materials and methods. A scheme of the different vector inserts can be viewed in Figures $1 \mathrm{a}-\mathrm{c}$. After $24 \mathrm{~h}$ transfection, the cells were exposed with or without $15 \mathrm{ng} \mathrm{ml}^{-1} \mathrm{TNF} \alpha$ for $1 \mathrm{~h}$ before transcriptional activities were measured. The relative luciferase activity showed that the IL1B GGCT haplotype had higher transcriptional activity compared with the $I L 1 B$ ACTC haplotype (Figure 2a) and treatment with TNF $\alpha$ did not have any marked effects. However, we found that when normalizing the data towards non-treated transcriptional activity of the most common haplotype (GGCT), TNF $\alpha$-induced transcriptional activity was significantly higher for the GGCT haplotype vector compared with the ACTC haplotype vector (Figure 2b).

\section{The effect of the IL1B G-1464C and the IL1B G-3893A SNPs on} transcriptional activity

The luciferase activity of unexposed cells transfected with vector containing the most common allele (IL1B $-1464 \mathrm{G}$ or $-3893 \mathrm{G}$ ) were used as reference. The results showed that $I L 1 B-1464 \mathrm{C}$ had a higher fold increase in transcriptional activity compared to $-1464 \mathrm{G}$ (Figure 2b) upon TNF $\alpha$ exposure. IL1B G-3893A showed no differences in transcriptional activity (Figure $2 \mathrm{~b}$ ).

Specific transcription factor binding pattern for IL1B - 1464C SNP We previously analyzed transcription factor binding patterns around the IL1B T-31C SNP by the use of EMSA, ${ }^{8,10}$ where we found that YY1 bound to the $I L 1 B-31 \mathrm{C}$ allele and regulated the expression of $I L 1 B .{ }^{14}$ Here, we characterized the transcription factor binding patterns around the -1464 (Figure 3a) and -3893 (Figure 3b) SNPs by the use of EMSA. Our results showed a transcription factor complex binding specifically to the $-1464 \mathrm{C}$ allele, analysis of the arbitrary densitometric units confirmed significant binding to

\section{a}

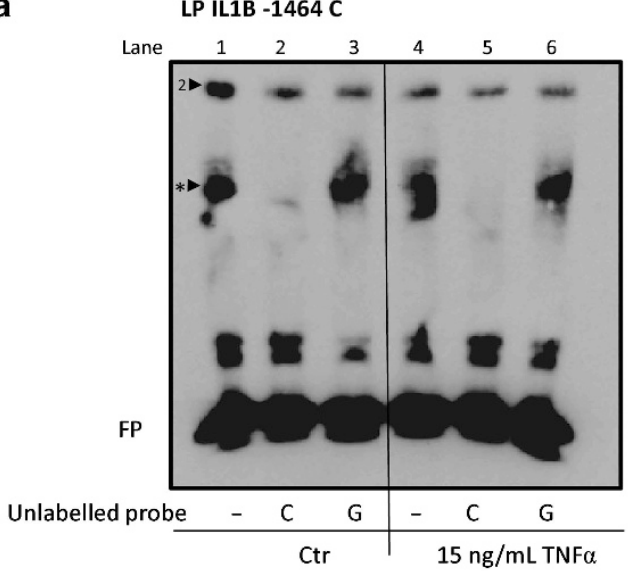

b

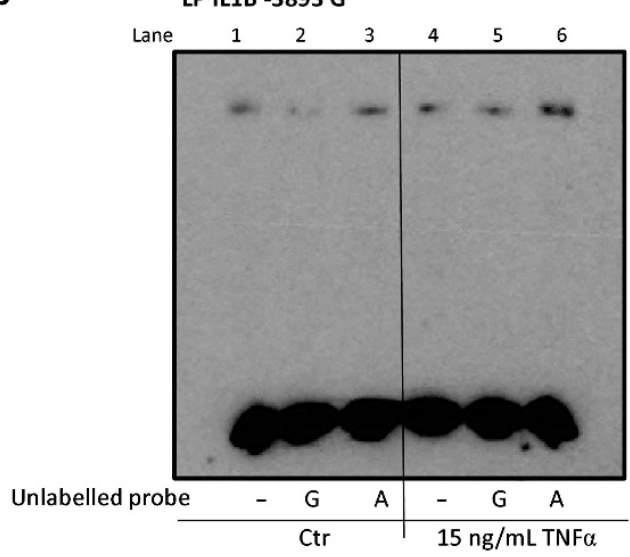

LP IL1B -1464 G

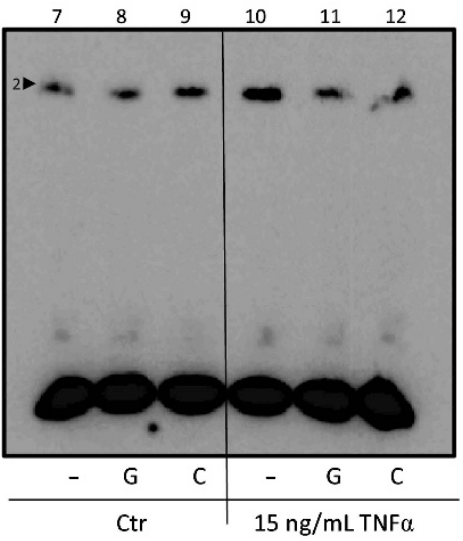

LP IL1B -3893 A

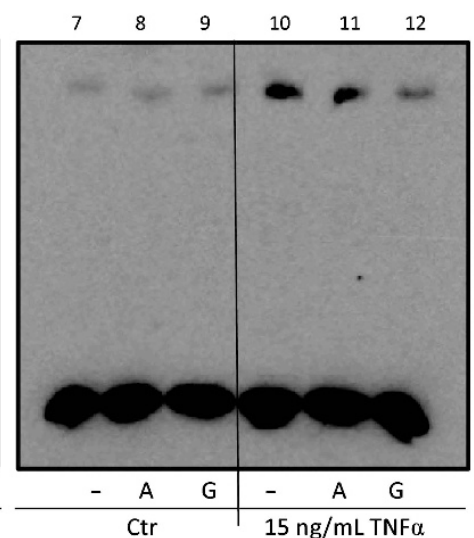

Figure 3 EMSA competition analysis. (a) Labeled probes flanking the -1464 C polymorphism (lane 1-6) or -1464G (lane 7-12) polymorphism were incubated with nuclear extracts exposed with (lane 4-6; 10-12) or without (lane 1-3; 7-9) $15 \mathrm{ng} \mathrm{ml}^{-1} \mathrm{TNF} \alpha$ for $1 \mathrm{~h}$. For competition analyses, unlabeled $-1464 \mathrm{C}$ (lane 2, 5, 9 and 12) or $-1464 \mathrm{G}\left(3,6,8\right.$ and 11) was added before the labeled probe. ${ }^{\star}$ denotes $-1464 \mathrm{C}$-specific band; for densitometric analysis, the upper band (2) was used (see Supplementary Figure 1). (b) Labeled probes flanking the $-3893 \mathrm{G}$ polymorphism (lane 1-6) or -3893A (lane 7-12) polymorphism were incubated with nuclear extracts exposed with (lane 4-6; 10-12) or without (lane 1-3; 7-9) $15 \mathrm{ng} \mathrm{ml}-1 \mathrm{TNF} \alpha$ for $1 \mathrm{~h}$. For competition analyses, unlabeled -3893G (lane 2, 5, 9 and 12) or $-3893 \mathrm{~A}(3,6,8$ and 11) was added before the labeled probe. FP, free probe; LP, labeled probe. 
the $-1464 \mathrm{C}$ allele in the different experiments performed (Supplementary Figure 1). There were no differences in binding patterns upon TNF $\alpha$ exposure for either -1464 or -3893 . We did not observe binding of transcription factors for the sequence surrounding the IL1B -3893 SNPs.

In silico analysis has shown that the transcription factor $\mathrm{C} / \mathrm{EBP} \beta$ shares more similarity to the $-1464 \mathrm{C}$ sequence compared with the $-1464 \mathrm{G}$ sequence. ${ }^{5}$ Based on these results, we performed supershift analysis on the $-1464 \mathrm{SNP}$ with antibodies raised against $\mathrm{C} / \mathrm{EBP} \beta$ (Figure 4a). We did not detect any shift in band when the nuclear extracts were incubated with the C/EBP $\beta$ antibody. The quality of the antibody was verified with western blot analysis (Figure $4 \mathrm{~b}$ ) on total cell lysates.

\section{DISCUSSION}

We previously found that a certain haplotype (IL1B $-3893,-1464$, -511 and -31 ) in the $I L 1 B$ gene regulatory region was overrepresented in lung cancer patients. The haplotypes also affected $I L 1 B$ mRNA expression, which is a direct downstream target of the IL1B haplotypes in the human lung. ${ }^{5}$ In the present study, we constructed

a
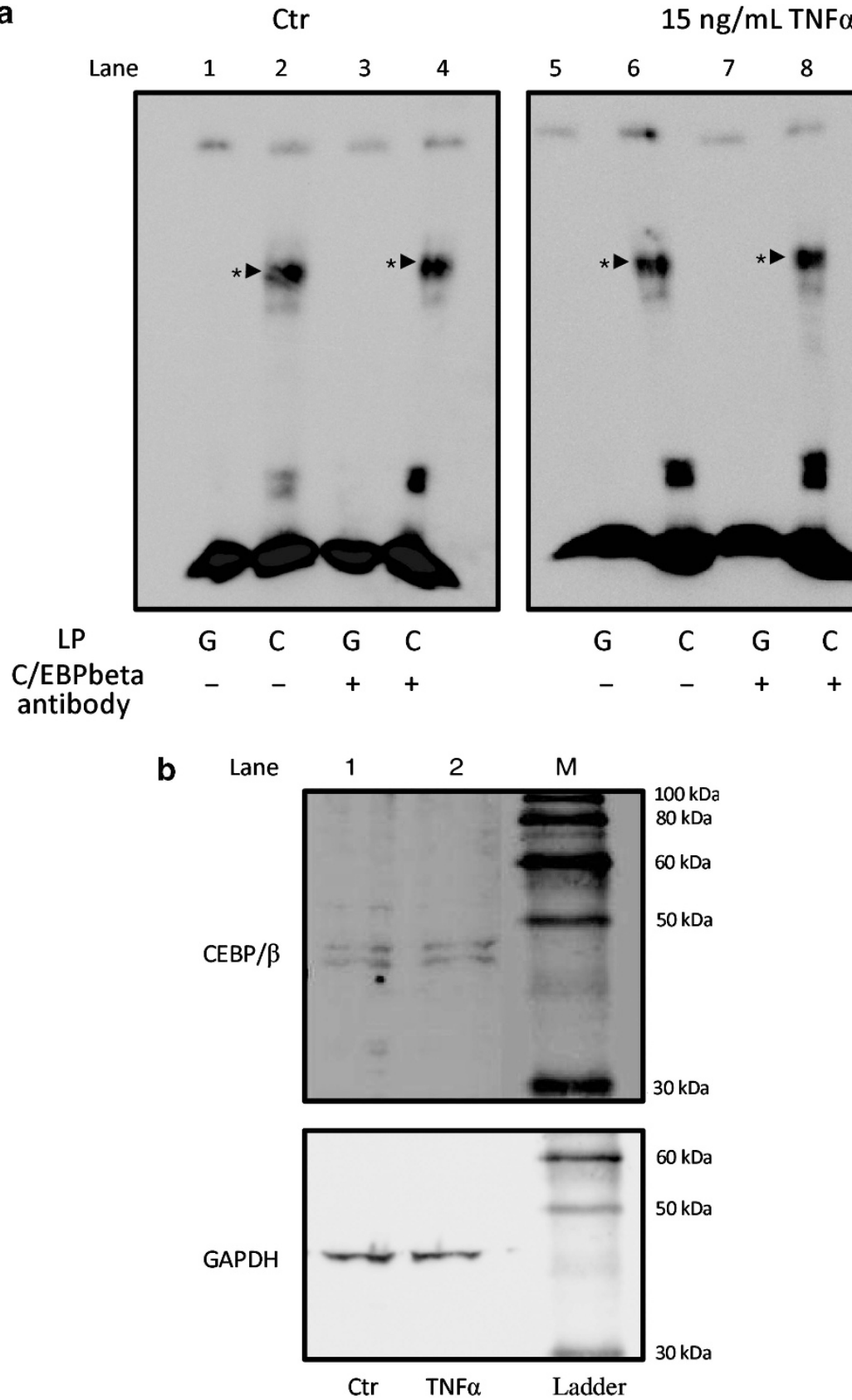

Figure 4 EMSA supershift analysis. (a) Labeled probes were incubated with nuclear extracts exposed with (lane 1-4) or without (lane 5-8) 15 ng ml-1 TNF $\alpha$ for $1 \mathrm{~h}$. Lane 1, 3, 5 and 7 were incubated with a probe flanking the $-1464 \mathrm{G}$ polymorphism. Lane 2, 4, 6 and 8 were incubated with a probe flanking the $-1464 \mathrm{C}$ polymorphism. For supershift analyses, antibodies raised against C/EBP $\beta$ (lane 3, 4, 7 and 8 ) were pre-incubated with the nuclear extracts and probes. * denotes the C-specific band. (b) C/EBP $\beta$ protein levels in A549 cells exposed or not to $15 \mathrm{ng} \mathrm{ml}^{-1}$ TNF $\alpha$ for $1 \mathrm{~h}$. GAPDH was used as a loading control. FP, free probe; LP, labeled probe; M, protein size marker (Lane 1) (Lane 2). 
reporter vectors containing the haplotypes being either protective (IL1B ACTC) or increasing (IL1B GGCT) lung cancer risk. The reporter vectors were designed so that the complete sequences between the -511 and -31 SNPs were included. However, several SNPs are located in the $I L 1 B$ regulatory region, ${ }^{6}$ to avoid a potential effect of these SNPs, we included $200 \mathrm{bp}$ surrounding the -1464 and -3893 SNPs. Our results showed that the transcriptional activity of IL1B GGCT was higher compared with IL1B ACTC. This is in line with our previous results measured on $I L 1 B$ expression in normal lung tissue. ${ }^{5}$ Transcription factor binding and transcriptional activity has previously been studied for the IL1B -31 and -511 SNPs. ${ }^{6-8,10}$ Chen et al. ${ }^{6}$ studied the effect of $I L 1 B$ gene-regulatory haplotypes in the human monocyte cell line THP-1 stimulated with lipopolysaccharide. They found that when IL1B $-31 \mathrm{~T}$ was present in the haplotype transcriptional activity was increased compared to the presence of $I L 1 B-31 \mathrm{C}$. They also found specific transcription factor binding to the variant $I L 1 B-31 \mathrm{C}$ allele. The IL1B T-31C SNP is located in the TATA-box of the $I L 1 B$ gene and a $C$ in the -31 position results in its disruption from TATAAA to CATAAA. Several studies have shown that the variant C-allele of the IL1B -31 SNP has increased transcription factor binding. ${ }^{6,8,10}$ However, although they did not detect any allelic differences in transcription factor binding patterns as observed with EMSA, Chen et al. found that the IL1B $-511 \mathrm{~T}$ SNP resulted in increased transcriptional activity and that the effect of $I L 1 B-511$ T overruled the IL1B $-31 \mathrm{~T}$ allele. El-Omar et al. ${ }^{7}$ also studied the effects of $I L 1 B-511$ SNP, but dedicated most of the attention to the $I L 1 B-31$ SNP and suggested the effect observed in population studies of $I L 1 B-511$ was due to its strong linkage with $I L 1 B-31$.

Our results showed increased transcription factor binding to the variant IL1B - 1464C allele, which also showed a higher fold transcriptional activity compared to the G-allele. This is in line with other studies where $I L 1 B-1464 \mathrm{C}$ has been shown to have increased nuclear protein binding, as well as increased transcriptional activity. ${ }^{6,9}$ In silico analysis of the sequence surrounding the IL1B G-1464C SNP has shown that $\mathrm{C} / \mathrm{EBP} \beta$ binds both to $I L 1 B-1464 \mathrm{G}$ and $\mathrm{C}$ sequence; however, its consensus binding sequence shares more similarity with the $-1464 \mathrm{C}$ sequence. ${ }^{5}$ Therefore, we wanted to test if C/EBP $\beta$ was the C-specific band characterized in the EMSA analysis. Our EMSAsupershift results did not show any shift or reduction of the C-specific band, indicating that this region is regulated by other transcription factor(s). IL1B G-1464C has been shown to be in linkage disequilibrium with $I L 1 B \quad \mathrm{C}-511 \mathrm{~T}$ and $I L 1 B$ T-31C, where the $-1464 \mathrm{G}$-allele is linked with $-511 \mathrm{C}$ and $-31 \mathrm{~T}^{5,6,12}$

We previously found an association with IL1B G-1464C and G-3893A SNPs and lung cancer risk. ${ }^{5}$ In the present study, we performed transcriptional activity of each SNP separately as well as in a haplotype context with other previously reported SNPs. We found that $-1464 \mathrm{C}$ had higher transcriptional activity compared with the $-1464 \mathrm{G}$ allele. These results further indicate that although $-1464 \mathrm{C}$ alone showed higher transcriptional activity, it did not seem to have a similar effect in a haplotype context where the haplotype with a $G$ allele at -1464 (GGCT haplotype) had the highest effect on transcriptional activity. There were no differences in transcriptional activity for the G and A allele of the -3893 SNP, which may suggest the $\mathrm{T}$ allele of T-31C SNP to have the critical effect on GGCT haplotype. In future studies, it would be interesting to study the haplotypes effect on COX-2 and IL-6, which are downstream targets in the IL- $1 \beta$ signaling pathway.

These results support the finding that the haplotype IL1B GGCT has a stronger impact on activation of transcription in the lung. Although the $I L 1 B-1464 \mathrm{C}$ vector showed higher transcriptional activity and also specific transcription factor binding, it did not seem to impact the transcriptional activity of the haplotype vector in a similar manner. The lower transcriptional activity observed with the IL1B ACTC haplotype may be explained by disruption of the TATAbox by the IL1B $-31 \mathrm{C}$ allele and the recruitment of the YY1 transcription factor to this region. We previously found that the GGCT and ACTC haplotypes had differential effect on the IL1B mRNA levels in normal lung tissues of lung cancer patients where the individuals with the GGCT had higher expression compared with the ACTC haplotype. ${ }^{5}$ We believe that these results support the in vitro evidence provided for increased transcriptional activity of the GGCT haplotype in the present paper.

\section{ACKNOWLEDGEMENTS}

Funds were provided by the Norwegian Research Council and Norwegian Cancer Society. Nina E Landvik is a recipient of a fellowship from the Norwegian Cancer Society and Solbergs Cancer Legacy.

1 Elaraj, D. M., Weinreich, D. M., Varghese, S., Puhlmann, M., Hewitt, S. M., Carroll, N. M. et al. The role of interleukin 1 in growth and metastasis of human cancer xenografts. Clin. Cancer Res. 12, 1088-1096 (2006)

2 Lewis, A. M., Varghese, S., Xu, H. \& Alexander, H. R. Interleukin-1 and cancer progression: the emerging role of interleukin-1 receptor antagonist as a nove therapeutic agent in cancer treatment. J. Transl. Med. 4, 48 (2006).

3 Auron, P. E. \& Webb, A. C. Interleukin-1: a gene expression system regulated at multiple levels. Eur. Cytokine Netw. 5, 573-592 (1994).

4 Enquobahrie, D. A., Rice, K., Williams, O. D., Williams, M. A., Gross, M. D. Lewis, C. E. et al. IL1B genetic variation and plasma C-reactive protein level among young adults: the CARDIA study. Atherosclerosis 202, 513-520 (2009).

5 Landvik, N. E., Hart, K., Skaug, V., Stangeland, L. B., Haugen, A. \& Zienolddiny, S. A specific interleukin-1B haplotype correlates with high levels of IL1B mRNA in the lung and increased risk of non-small cell lung cancer. Carcinogenesis 30, 1186-1192 (2009).

6 Chen, H., Wilkins, L. M., Aziz, N., Cannings, C., Wyllie, D. H., Bingle, C. et al. Single nucleotide polymorphisms in the human interleukin-1B gene affect transcription according to haplotype context. Hum. Mol. Genet. 15, 519-529 (2006).

7 El-Omar, E. M., Carrington, M., Chow, W. H., McColl, K. E., Bream, J. H., Young, H. A et al. Interleukin-1 polymorphisms associated with increased risk of gastric cancer. Nature 404, 398-402 (2000)

8 Hart, K., Haugen, A. \& Zienolddiny, S. Allele-specific induction of IL1B -31T/C promoter polymorphism by lung carcinogens. Mutat. Res. 656, 14-18 (2008).

9 Lee, K. A., Ki, C. S., Kim, H. J., Sohn, K. M., Kim, J. W., Kang, W. K. et al. Nove interleukin 1 beta polymorphism increased the risk of gastric cancer in a Korean population. J. Gastroenterol. 39, 429-433 (2004).

10 Lind, H., Haugen, A. \& Zienolddiny, S. Differential binding of proteins to the IL1B -31 T/C polymorphism in lung epithelial cells. Cytokine 38, 43-48 (2007)

11 Rogus, J., Beck, J. D., Offenbacher, S., Huttner, K., lacoviello, L., Latella, M. C. et al. IL1B gene promoter haplotype pairs predict clinical levels of interleukin-1beta and C-reactive protein. Hum. Genet. 123, 387-398 (2008).

12 Vangsted, A. J., Klausen, T. W., Abildgaard, N., Andersen, N. F., Gimsing, P., Gregersen, $\mathrm{H}$. et al. Single nucleotide polymorphisms in the promoter region of the IL1B gene influence outcome in multiple myeloma patients treated with high-dose chemotherapy independently of relapse treatment with thalidomide and bortezomib. Ann. Hematol. 90, 1173-1181 (2011).

13 Zienolddiny, S., Ryberg, D. Maggini, V., Skaug, V., Canzian, F. \& Haugen, A. Polymorphisms of the interleukin-1 beta gene are associated with increased risk of non-small cell lung cancer. Int. J. Cancer 109, 353-356 (2004).

14 Landvik, N. E., Tekpli, X., Anmarkrud, K. H., Haugen, A. \& Zienolddiny, S. Molecular characterization of a cancer-related single nucleotide polymorphism in the proinflammatory interleukin-1B gene. Mol. Carcinog (e-pub ahead of print 29 March 2012; doi:10.1002/mc.21910)

Supplementary Information accompanies the paper on Journal of Human Genetics website (http://www.nature.com/jhg) 